\title{
On the Emotive-Evaluative Meaning of Phraseological Units
}

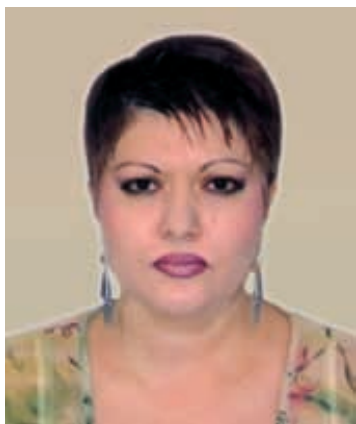

Gayane Yeghiazarian

The content of information is two-fold: it has logical 1 and emotive-evaluative components. Logical meaning is the precise naming of a feature of the phenomenon or object, the name by which we recognize the whole of the concept (This meaning is also called referential or direct).

"Emotive meaning also materializes a concept in the word, but, unlike logical meaning, emotive meaning has reference not directly to things or phenomena of the objective reality, but to the feelings and emotions of the speaker towards these things or to the emotions as such" (Galperin, 1977: 66).

Therefore emotive meaning bears reference to things, phenomena or ideas through a kind of evaluation.

To establish meanings as features of types of word groups, we have to start from the fundamental and referential distinction between referential and attitudinal meanings. "Referential meaning is defined as merely denoting, or referring to something, either by naming it or by pointing it out, whereas attitudinal meaning is defined as the expression of an attitude of the speaker towards the facts of the objective reality" (William de Groot, 1975:69).

One of the aspects of meaning that has variously been called "cognitive" or "denotational" is by no means the only kind of meaning and it is not even clear whether it is the most important. Much of what we say is not a statement of a fact but an evaluation (Palmer, 1982:29).

All the above-mentioned definitions of word meaning anticipate the necessity of identifying the phenomenon of connotation.

Many scholars emphasize the existence of some additional meaning which is secondary to denotative meaning, and which is variously called connotation or signification (Galperin, 1977; Àđí î ëüä, 1981; Àđóò í î âà, 1976; Áàdò, 1975; Stierle, 1975).

There is no unanimity of opinion among scholars as to the definition of connotation. But they are unanimous in admitting the existence of emotive, evaluative and expressive components of connotation (Ø àôî âneèèé, 1986:14). Connotation may more or less generally be defined as "emotional, social or moral value that is associated with a word" (Maclin, 1996:119).

The semantic pivot of connotation is the emotive component, which is always both evaluative and expressive.

As J. A. Leech states, "A distinction should be made between evaluative meaning, on 
the one hand, and feeling-tone, on the other. By evaluative meaning we mean a type of designative meaning in which the overt reference is made of values, whether aesthetic, moral, ethical or otherwise (the type of meaning found in the antonymies 'good/bad', 'right/wrong', 'nice/nasty'). These meanings, it will be poticed, are organized in terms of synonymy and antonymy, and can be handled by componential analysis. In contrast, a sentence, such as $I / l$ knock your block off conveys the hostility of its user in no uncertain terms, but this hostility cannot be pinned down to the meaning of any particular part of the utterance" (Leech, 1969:84-85).

Many linguists (Bolinger, 1971; Fahraus, 1980) have paid special attention to the problem of evaluation and discussed this phenomenon in their works.

Our mind has elaborated a system of evaluative concepts which are deprived of emotive layers. With the help of evaluative concepts evaluative statements are made which may or may not be accompanied by the emotions of the speaker (author) and which express only logical but not emotional attitude towards the objective reality.

In order to make the speaker's attitude emotional, it is necessary to insert an emotional element into the concept of logical evaluation. If there exists an emotive component in the meaning of the linguistic unit, the evaluative component is coloured with emotiveness. Evaluative elements in language and speech cannot impart any emotions to the recipient without interaction with expressive elements. The category of expressiveness may be understood as a kind of intensification of an utterance. Interaction of expressiveness and evaluation, under certain circumstances, may result in the formation of emotive evaluation, which can evoke the recipient's adequate emotive response.

So, the content of evaluation may not only be logical (intellectual) but also logicalemotional. Logical content provides the basis for any evaluation. Emotive evaluation has objective-subjective character in compliance with the systen of objective and subjective interrelations. Emotiveness is always evaluative and expressive. Expressiveness and evaluation may be included in the phrase separately from each other and from emotiveness (if the phrase is not emotive). Emotiveness alone, without any expressive component cannot be found in a phrase. In the phrase do somebody's heart good-make somebody happy, do somebody a favour - the semantic differential sign is shaped as pleasant sensation (emotion), positive attitude (evaluation) and, as it is used metaphorically, it is expressive as well. Or, in the phrase bring somebody's heart into his mouth - to frighten somebody - the semantic differential sign is shaped as unpleasant sensation (emotion), negative attitude (evaluation), and is expressive as well.

It should be noted that the vocabulary of negative evaluation prevails over the vocabulary of positive evaluation. This phenomenon is explained by socialpsychological factors. All that is good is considered to be standard, but deviation from the standard has a wide range of various manifestations reflected in the denotative meaning of the phrase. For instance, in dictionaries we can find more than forty phrases with 'head" which mean "a stupid or stubborn person" (block head; bone head; cabbage head; hammer head; pumpkin head; square head; balloon head, hard head; leather head, etc.), whereas positively evaluated phrases with the same word 'head' are very rare (good head - an agreeable person; clear head - bright mind, etc.). 
There are two classes of phraseological units in the English language: expressiveemotive (hand in glove - in close, oflen conspiratorial, association and/or co-operation (with each other) and expressive only (hand in hand - side by side with hands linked). The former are ontologically able to contain emotive evaluations (either positive or negative): a sight for sore eves; an ass in a lion's skin; a wolf in sheep's clothing; have butterflies in one s belly: wet behind the ears, etc.

It is proved that the vast majority of phraseological units possess emotive connotations in their meaning. All emotive units are certain to contain an expressive component in their denotation, but not all expressive units assume the presence of emotive connotation.

Evaluative-emotive meaning in phrases can be explicit and implicit. Explicit meaning is permanent, and evident both in the context and beyond its limits. Phrases with an evaluative component in their meaning include evaluative words with a motivated value-loaded (positive or negative) sign which is in the semantic content of the phrase and correspondingly impart positive or negative enotions, e. g. have a heart of gold - have a noble, kind, helpful, loyal, etc. nature; have a broad back - be generous; clean hands - an innocent and honest person; (as) busy as a bee - very busy, occupied. active, especially in a satisfying way (positive value-loading); turn ones back on somebody - leave, abandon somebody; make somebody's heart bleed - cause one/somebody to feel extreme sorrow or pity; heart of stone - hard-hearted, unsympathetic person (negative evaluation), etc. Implicit meaning is hidden in the semantic deptl of the phrase and can be revealed only by the method of thorough semantic absorption into the phrase until a certain emotive-evaluative meaning is found. e. g. calk through one's hat - to say trash; put a hat on a hen - to do useless things; when pigs fly - never; to give somebody the rough side of ones tongue - to reprimand somebody; tickle somebody's ribs - to amuse somebody; set one s teeth on edge - to irritate, to annoy somebody; keep one's/somebody's nose to the grindstone - work persistently and hard, with the implication that the work is difficult, monotonous or dull, etc. The evaluative-emotive meaning of some phrases is sometimes so strong that it suppresses the co-existing logical meaning.

Emotive evaluation may be usual (known to all the speakers of the language) or occasional. Occasional emotive evaluation may have two variants: it can be individual or collective. The expressive phrase around the corner, which means "very near, at hand", has acquired collectively disapproved emotiveness and negative evaluation. Since Herbert Hoover, the 31 st president of the USA used to say all too often at the time of his presidency (Prosperity is jtist around the corner!), gradually people lost confidence in his words, and since then the phrase has been used negatively when the purpose is to hint that something may not be said sincerely or in earnest.

As far as expressive phrases are concerned, their emotive evaluation is realized only in the context. For example, the expressive phrase shrug one's shoulders can mean different things in different contexts and is to be understood accordingly. One may shrug one s shoulders helplessly or as a sign of regret, astonishment, bewilderment, hesitation or doubt, lack of confidence, understanding or information. 
The expressive phrase come back empty-handed may convey 'sick humour', when a person speaks about himself in a positive context or may be used as a gloating remark, when a person speaks of somebody else. In this case the phrase can be replaced by its various synonyms, thus ensuring enotive-evaluative effect: get nothing for one's pains; be left holding the bag; be left out in the cold; come back non the wiser and last but not least, go away with a flea in one's ear.

Some phrases, such as hand over fist (hand over hand); have a hand in something; by leaps and bounds are able to agree with both positive and negative overtones. Their potential can be realized only according to the stylistic colouring of the context. Thus, for example,

He didn't think of concealing his crimes and was now franklv telling us about them including the fact that he had a hand in the murder of that man. (A. Christie)

The context conveys negative emotive evaluation rather vividly. The same phrase has a sign of positive overtones in the following context:

Whenever he sees me in a new dress, or notices anything fresh about the house, he always savs, "I suppose Pippa had a hand in that!". (A. Furness)

When the context cannot serve as the source of emotive evaluation, the necessary emotive evaluation may be introduced into the expressive phrase by means of negative or positive evaluative elements:

The Govermment took a positive hand in the attempt to repress the Trade Unions, $b y$ encouraging the emplovers. (The Guardian)

The phrase take a hand in something is expressive only. The author used the word 'positive' to ensure his definite evaluation of the Government's actions and to eliminate all the possible doubts of the recipient in this respect.

Expressive-evaluative units, such as to welcome somebody with open arms, are in no need of any additional logical (intellectual) evaluation as they contain two components of meaning, i.e. evaluative and expressive. However, sometimes not only expressive, but also expressive-evaluative phrases can gain emotiveness in a certain context. Expressive-evaluative units may be handled not in their fixed forms but with modifications. The use of such a unit in a modified form will always attract our attention. Sometimes the "injection of a new vigour" (I. R. Galperin, 1977:142) into the phrase causes a semantic re-evaluation of its generally accepted meaning.

Expressive-evaluative units may require additional expressive means to secure the recipient's emotive evaluation. They may acquire emotive-evaluative meaning in the context with the help of "put-in" words (go to a better world - go to a much better world; between two fires - between not only two but three fires; cannon fodder - fresh cannon fodder; etc). Or:

Darling, it's as plain as the nose on your beautiful face. (W. S. Maugham) 
The final drama was perfectly planned and timed. There was a sleeping draught for me, in case I might put an inconvenient finger in the pie. (A. Christie)

They all go to our friend Mont with some tale or other, Mr. Desert - he has a very soft heart. (J. Galsworthy)

.. She nobbled Jasper Gibbons. In a little while he was eating out of her soft hand. She was admirable. (W. S. Maugham)

"Set of evaluations", which is a chain of positive/negative evaluation of the same language sign may also be the source of strong expressiveness, emotiveness and valueloading.:

... said the dwarf, thrusting his head in at the door - "My per, my pupil, the apple of my eye, hey, hey!". (Ch. Dickens. The Old Curiosity Shop)

There can also be occasional structural semantic changes in phrases evoking strong expressiveness through the second component of emotive evaluation. For example,

And so, in a sense, the uffair, no matter what happens out there tonight, will still be in the family; the skeleton (if it be a skeleton) still in the closet.

(W. Faukner, Absalom, Absalon!)

In the given example the phrase skeleton in the closet is used in a peculiar way, thus. making the reader re-appraise the hackneyed phrase.

A phrase having positive value load is able to make the whole text unit sound ironical when used in a context with negative overtones:

Holcomb [a police sergeant] will move heaven and earth to keep everyone believing $I$ broke into that apartment and purloined that tape. (E. S. Gardner)

The phrase move heaven amd earth, which means "do one's best", has positive overtones but in the context above is used negatively.

Sometimes a traditionally accepted evaluation sign can turn into the opposite valueloaded sign as a result of substitution of the components: one good turn deserves another (positive value) $\rightarrow$ Did one bad turn deserve another? (U. Sinclair) Or:

But now if he hands over the tapes, people say he has doctored them, and even when he staggers firm one move to another, he is met with the cynical remark: A crisis a day keeps impeachment away. (International Herald Tribune)

The remark a crisis a day keeps impeachment anav is made up on the basis of the saying an apple a dav keeps the doctor awav, which has positive overtones. The components of the innovative juxtaposition 'crisis' and 'impeachment' belong to the confext and convey negative overtones of meaning.

In various contexts synonymous phrases may be used, as they have different shades of meanings. For example, when one wants to deceive or fool somebody, one may pull 
somebody's leg (often by saying something that is not intended to be taken seriously, a sort of a joke), throw dust in somebody's eyes or pull the wool over somebody's eyes (by preventing a person from seeing the true state of affairs). And it is the context that determines which of these phrases is to be used.

To conclude, the emotive-evaluative content takes shape under the influence of: a) denotational (logical) evaluation, which may be in the text itself or beyond the text limits; b) emotions that usually accompany denotational evaluation; c) expressive means and stylistic devices of the language that form or specify the character of those emotions which in their turn, make the denotational evaluation more pronounced and definite. The diagram of the notion of emotive evaluation may be expressed in the following forn:

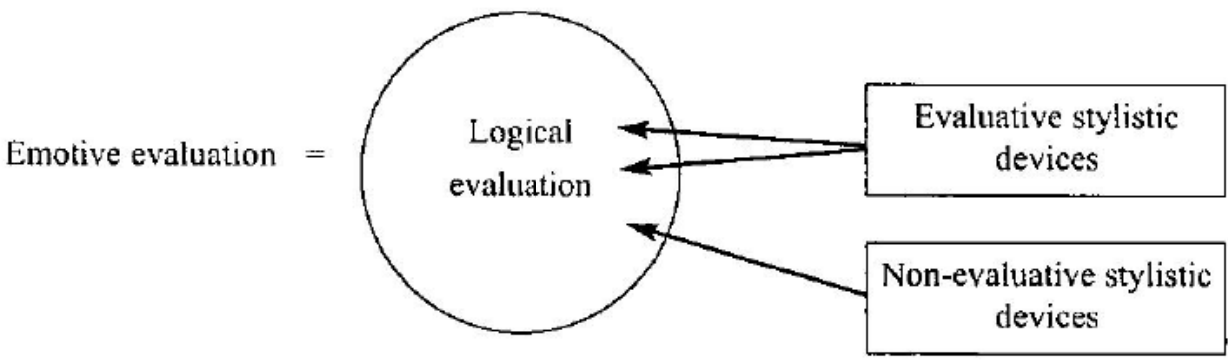

The emotive-evaluative meaning of a word is somewhat unstable and highly variable: it can differ from one speaker to another, from one social group to another, from one situation to another. In spite of its vagueness and lack of visible contours, it is a linguistic reality which can be studied by psychological, as well as philological methods.

\section{References:}

1. Арнольд И. В. Стилистика английского языка. М., 1981.

2. Арутюнова Н. Д. Предложение и его смысл. М., 1976.

3. Барт Р. Основы семиологии. // Структурализм: "за" и "против". М., 1975.

4. Шаховский В. И. Эмотивный компонент значения и методы его описания (Учебное пособие к спецкурсу). Волгоград, 1986.

5. Bolinger D. Degree Words. Mouton, 1971.

6. Fahraus A. Syntactic-semantic Value-loading in English. Copenhagen, 1980.

7. Galperin I. R. Stylistics. M., 1977.

8. Leech.G. N. Towards a Semantic Description of English. London, 1969. 
9. Maclin A. Reference Guide to English: A Handbook of English as a Second Language. Washington, 1996.

10. Palmer F. R. Semantics - A New Outline. Moscow, 1982.

11. Stierle K. Text als Handlung. München, 1975.

12. William de Groot A. Classification of Word-Groups. // Readings in Modern English Lexicology. Leningrad, 1975.

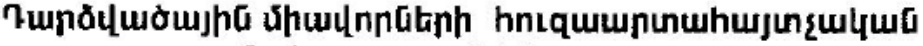

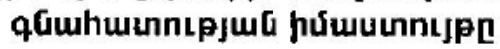

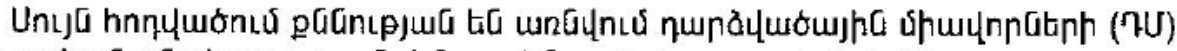

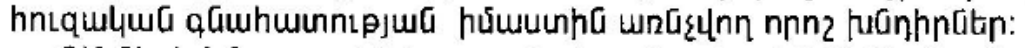

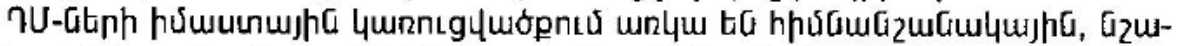

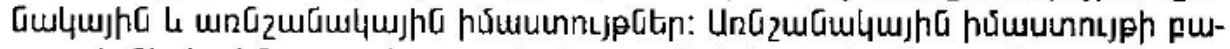

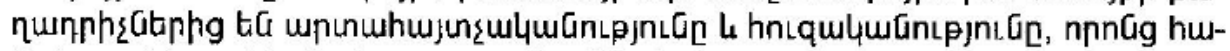

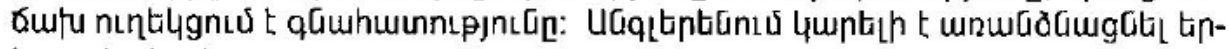

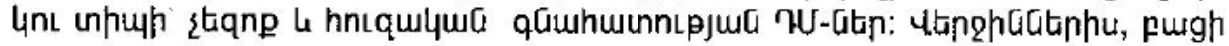

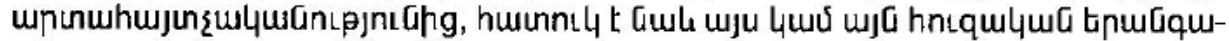

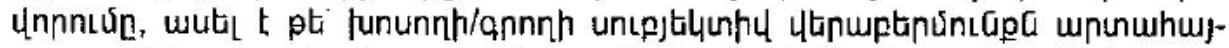

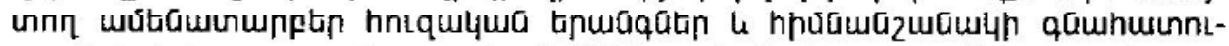

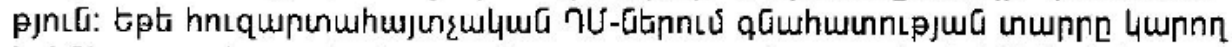

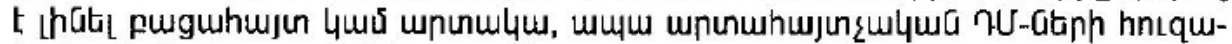

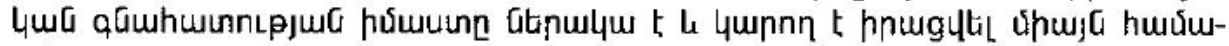
unteutnntt: 